\title{
Transverse process strut and titanium mesh cages in the stability reconstruction of thoracic single segment tuberculosis: a retrospective single-center cohort study
}

Weiyang Zhong ${ }^{1}$, Xinjie Liang ${ }^{2}$, Ke Tang ${ }^{1}$, Xiaoji Luo ${ }^{1}$ and Zhengxue Quan ${ }^{1 *}$

\begin{abstract}
Background: A retrospective and comparative study of transverse process strut (TPS, Group A) compared with titanium mesh cages (TMCs, Group B) in the reconstruction of thoracic stability through the one-stage posterior approach to treat single-segment tuberculosis.

Methods: Sixty patients from January 2013 to December 2016 were analyzed and divided into two groups. The following data of clinical and radiographical assessments were observed preoperatively, postoperatively and during follow-up (FU).

Results: The patients were followed up for an average of $50.20 \pm 25.10$ months (Group A) and $48.70 \pm 27.30$ months(Group B) without significant difference. No significant differences were found in the mean of operation time in minutes, blood loss, hospitalization time, drainage and follow-up duration between the groups. The VAS, ODI, ESR and CRP were reduced significantly at the final FU compared with the preoperation values and there was no significance between the groups. Neurological deficits were improved in all patients at the final FU without significant difference between the groups $(P>0.05)$. The bony fusion times were $5.85 \pm 1.82$ months and $8.4 \pm 5.1$ months with significant difference $(P<0.05)$. Comparing with the preoperative values, the kyphosis angle significantly improved, but at the final FU the significant difference was found between the groups $(P<0.05)$. The loss of the angular correction and the fused segmental height in group $A$ was lower than that in group $B(P<0.05)$.
\end{abstract}

Conclusions: TPS had a better osseous fusion rate, effective maintenance of fused segment stability which is a good bone graft for surgical management of single-segment thoracic spinal tuberculosis.

Keywords: Transverse process strut, titanium mesh cages, Thoracic spinal tuberculosis

\section{Background}

Human tuberculosis (TB) is a chronic and ancient disease characterized by weight loss and it is a cause of death and most cases of tuberculosis occur in developing countries. According to the World Health Organization (WHO), TB causes 1.81 million deaths in Asia each year

\footnotetext{
*Correspondence: quanzx18@126.com

'Department of Orthopedic Surgery, The First Affiliated Hospital of Chongqing Medical University, Chongqing, China

Full list of author information is available at the end of the article
}

and China has $78 \%$ new cases every year [1-4]. In recent years, the emergence of Acquired Immune Deficiency Syndrome (AIDS) and drug resistance has greatly increased the incidence of tuberculosis and made it a bigger threat, arousing considerable attention worldwide [5, 6]. The spine is involved in $50 \%$ of osteoarticular tuberculosis cases, spinal involvement is especially dangerous, as it can result in destruction of the vertebral body, spinal deformity and/or paraplegia. When the affected spine becomes unstable, the resulting deformity creates

(c) The Author(s). 2020 Open Access This article is licensed under a Creative Commons Attribution 4.0 International License, which permits use, sharing, adaptation, distribution and reproduction in any medium or format, as long as you give appropriate credit to the original author(s) and the source, provide a link to the Creative Commons licence, and indicate if changes were made. The images or other third party material in this article are included in the article's Creative Commons licence, unless indicated otherwise in a credit line to the material. If material is not included in the article's Creative Commons licence and your intended use is not permitted by statutory regulation or exceeds the permitted use, you will need to obtain permission directly from the copyright holder. To view a copy of this licence, visit http://creativecommons.org/licenses/by/4.0/. The Creative Commons Public Domain Dedication waiver (http://creativecommons.org/publicdomain/zero/1.0/) applies to the data made available in this article, unless otherwise stated in a credit line to the data. 
a risk of spinal cord compression. The goals of tuberculosis treatment are to eradicate the infection provide spinal stability and save the patient's life. Supportive care, chemotherapy and surgery are consistently effective in the management of spinal tuberculosis $[7,8]$.

When severe bone destruction, kyphosis, or nerve deficit occurs, surgical management still plays a significant role in curing spine tuberculosis. After debridement and decompression, many interbody bone grafts are used for to reconstruct spinal stability, such as the iliac crest which is the gold standard or fibula grafts and titanium mesh cages (TMCs) $[9,10]$. Autologous bone or allografts can achieve good bony fusion, however, they have some problems that limit their application. A number of studies have reported that TMCs shows significant potential for reliable spinal reconstruction and it offers excellent bone fusion, adequate sagittal profile maintenance and a low implant-related complications rate [11-15]. In our study, the transverse process strut (TPS) was used as a bone graft to reconstruct the stability of the spine. The purpose of the research was to investigate the clinical effect of TPS compared with TMCs for the surgical treatment of single-segment thoracic spinal tuberculosis.

\section{Methods}

\section{Patients}

This study was approved by the Institutional Review Board of The First Affiliated Hospital of Chongqing Medical University. Two treatment plans were involved in the routine clinical care. When communicating with patients before surgery, the advantages and disadvantages of the two types of management were fully introduced, so the patients could choose the right treatment for themselves. All surgical procedures were performed by the same senior surgeon.

From January 2013 to December 2016, 60 patients with single-segment thoracic spinal tuberculosis were treated and reviewed retrospectively in our department. In group A, 30 patients received TPS for the reconstruction and in group B, 30 patients underwent TMCs. Inclusion criteria: adult single-segment thoracic spinal tuberculosis who were indicated for surgery: increasing kyphosis, neurological deficits, bone destruction affecting the stability, the bone damage of the infected vertebral body did not exceed 1/2 the vertebral height, one-stage posterior approach for internal fixation, and reconstruction. Exclusion criteria: active tuberculosis of the lung and extrapulmonary organs, multiple-segment thoracic vertebral tuberculosis, cancer.

Chemotherapy with an HREZ standard chemotherapy regimen comprising isoniazid(H)(5-10 $\mathrm{mg} / \mathrm{kg} /$ day $)$, rifampi$\operatorname{cin}(\mathrm{R})(10 \mathrm{mg} / \mathrm{kg} /$ day $)$, ethambutol(E)(15 mg/kg/day), and pyrazinamide(Z)(25 mg/kg/day) was administered 3-4 weeks before the operation. Surgery was performed when the patient's erythrocyte sedimentation rate (ESR), C-reactive protein (CRP) and temperature recovered to normal or nearly normal. If the patient's neurological condition deteriorated rapidly, an urgent salvage operation was performed.

\section{Surgical technique and measurement}

In group A, the patient was placed in prone position after the administration of conventional tracheal anaesthesia. The posterior elements, including the lamina, facet joint and transverse process, were exposed with a midline incision. Pedicle screws were fixed on the basis of imaging and $\mathrm{C}$-arm X-rays to ensure their accuracy. After decompression and thorough debridement, the adjacent transverse process was cut off and trimmed to round cortical bone and double-sided cancellous bone (Fig. 1). Depending on the characteristics of the space after thorough debridement, one or more TPS was implanted in the anterior defect and the device was properly locked. Topical streptomycin $1.0 \mathrm{~g}$ and isoniazid $0.2 \mathrm{~g}$ mixed gel were applied. After surgery, negative pressure drainage was used to remove specimens and conduct bacterial cultures and pathology examinations. In group $\mathrm{B}$, the surgical procedure was similar to that described for group A. The only difference was that the trimmed TMCs (filled with removed cancellous bone) was implanted into the bone defect and fully connected to the upper and lower vertebral end-plates.

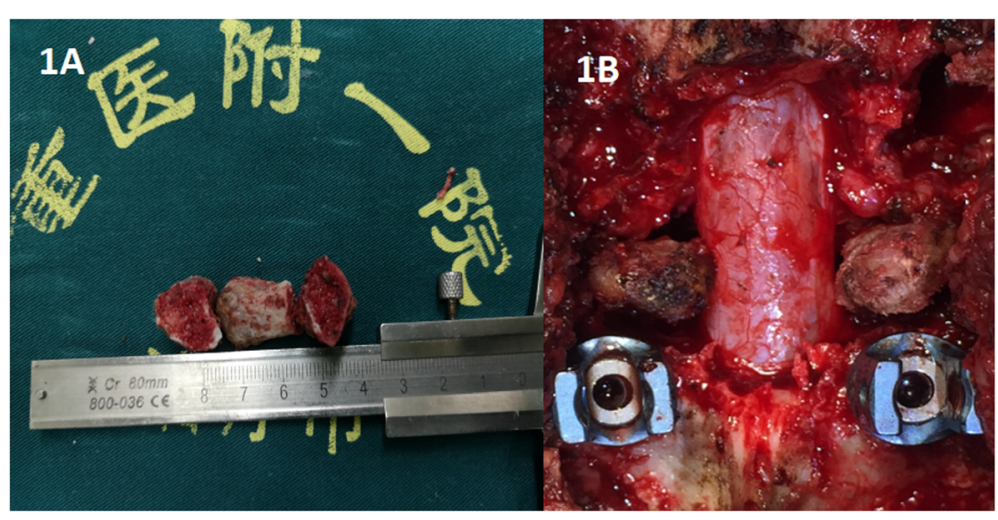

Fig. 1 Photographs of one, two or three trimmed transverse process that were implanted 

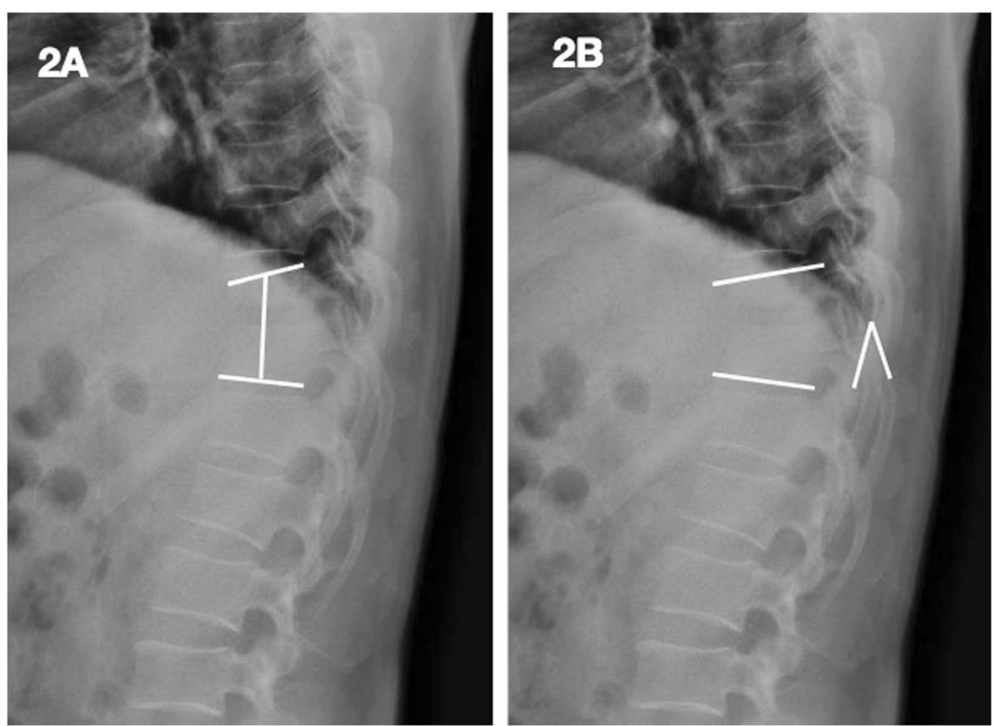

Fig. 2 Presentation of the measurement of the fused segmental height (a) and of the kyphosis angle (b)

The drainage tube was removed when less $50 \mathrm{ml} /$ day was drained from the surgical site. The patients received oral HREZ chemotherapy after surgery for 12 months, followed by 6-month regimens of HRE chemotherapy (12HREZ/1218HRE). Rehabilitation training and nutritional support began the day after surgery. Ambulation with a brace was allowed the third day after surgery. All patients were evaluated clinically and radiologically at one week and 3, 6 and 12 months after surgery and once a year thereafter.

For all patients, the following data were observed preoperatively, postoperatively, and during follow-up (FU): (1) the operation time, surgical blood loss, hospitalization time, drainage, bone fusion time (bone graft fusion was assessed using the radiologic criteria of Bridwell et al. [15], 2) kyphosis angle; neurological function (American Spinal Injury Association, ASIA); (4) Visual Analogue Scale (VAS) and Oswestry Disability Index (ODI); (5) erythrocyte sedimentation rate (ESR) and C-reactive protein (CRP). The fused segmental height (the distance between the midpoint of the superior endplate of the upper vertebral body and the midpoint of the inferior endplate of the lower vertebral body)) was measured (Fig. 2). The height loss was calculated with the following formula: (Height of 1 week post-operation) - (Height of subsequent followup).

According to the Cobb method, the kyphosis angle was defined as the angle formed between the superior endplate of the upper vertebral body and the inferior endplate of the lower vertebral body (Fig. 2). Loss of angular correction was calculated with the following formula: (Angle of 1 week post-operation) - (Angle of subsequent follow-up). The subsidence was defined as a decrease in the fused segmental height during the follow-up period greater than 3 mm compared with that on day 1 . All radiographic data and measurements in this study were reviewed by one senior spine surgeon and one senior radiologist.

\section{Statistics}

All statistic data were analysed with SPSS version 22.0 statistical soft ware (SPSS, Inc., Chicago, IL, USA). Quantitative data are presented as means and standard deviations. Repeated measures t-test was used for the statistical analysis of differences in mean values, and the chi-squared test was used for categorical data. Statistical significance was defined as a $p$ value $<0.05$.

\section{Results}

The patients were followed up for an average of $50.20 \pm$ 25.10 months (group A) and $48.70 \pm 27.30$ months (group B) without significant difference. No significant differences were found in the mean of operation time in minutes, blood loss, hospitalization time,drainage and follow-up

Table 1 Comparison of the baseline and postoperative data

\begin{tabular}{llll}
\hline & Group A & Group B & $P$ value \\
\hline No. of patients $(n)$ & 30 & 30 & \\
Male/female $(n)$ & $21 / 9$ & $16 / 14$ & \\
Mean age (years) & $46.23 \pm 17.20$ & $45.78 \pm 19.10$ & 0.912 \\
Hospital stay (days) & $17.31 \pm 4.23$ & $18.50 \pm 2.88$ & 0.874 \\
Surgery time (minutes) & $195.08 \pm 24.07$ & $190.30 \pm 26.15$ & 0.780 \\
Blood loss (ml) & $280.77 \pm 189.90$ & $300.77 \pm 150.60$ & 0.437 \\
Drainage (ml) & $436.92 \pm 193.81$ & $402.92 \pm 169.21$ & 0.356 \\
Mean fusion time (months) & $5.85 \pm 1.82$ & $8.4 \pm 5.1$ & 0.012 \\
Follow-up (months) & $50.20 \pm 25.10$ & $48.70 \pm 27.30$ & 0.650 \\
\hline
\end{tabular}


duration between the groups $(P>0.05)$ (Table 1$)$. The VAS, ODI, ESR and CRP were reduced significantly at the final FU compared with the preoperation values and there was no significant significance between the groups. Neurological deficits were notably improved in all patients at the final FU without significant difference between the $\operatorname{groups}(P>0.05)$ (Table 2$)$.

Spinal TB was completely cured and all patients achieved bone fusion. The bone fusion time was $5.85 \pm 1.82$ months in group A and 8.4 \pm 5.1 months in group B and the difference was significant. Comparing with the preoperative values, the kyphosis angle significantly improved, but at the final FU, the significant difference was found between the groups $(P<0.05)$. The loss of angular correction and fused segmental height in group A was lower than that in group B $(P<0.05)$ (Figs. 3, 4, and 5).

No complications, including bone graft failure, pleural effusion and wound infection, were recorded, with the

Table 2 Clinical and radiographic outcomes in each group

\begin{tabular}{|c|c|c|c|}
\hline Parameter & Group A & Group B & $P$ value \\
\hline \multirow[t]{2}{*}{ ESR $(\mathrm{mm} / \mathrm{h})$ change from before treatment to final follow-up } & $51.31 \pm 18.54$ & $58.12 \pm 15.32$ & 0.125 \\
\hline & $10.61 \pm 2.96^{*}$ & $12.52 \pm 1.25^{*}$ & 0.223 \\
\hline \multirow[t]{2}{*}{ VAS score change from before treatment to final follow-up } & $6.4 \pm 0.88$ & $6.7 \pm 0.45$ & 0.654 \\
\hline & $1.62 \pm 0.65^{*}$ & $1.71 \pm 0.35^{*}$ & 0.699 \\
\hline \multirow[t]{2}{*}{ ODI score change from before treatment to final follow-up } & $39.15 \pm 4.02$ & $40.05 \pm 3.22$ & 0.774 \\
\hline & $4.68 \pm 1.43^{*}$ & $4.83 \pm 1.15^{*}$ & 0.805 \\
\hline \multicolumn{4}{|l|}{ Severity of neurological deficits } \\
\hline \multicolumn{4}{|l|}{ Before treatment } \\
\hline \multicolumn{4}{|l|}{ ASIA A } \\
\hline \multicolumn{4}{|l|}{ ASIA B } \\
\hline ASIA C & 18 & 19 & 0.721 \\
\hline ASIA D & 10 & 8 & 0.735 \\
\hline ASIA E & 2 & 3 & 0.810 \\
\hline \multicolumn{4}{|l|}{ At the final follow-up } \\
\hline \multicolumn{4}{|l|}{ ASIA A } \\
\hline \multicolumn{4}{|l|}{ ASIA B } \\
\hline \multicolumn{4}{|l|}{ ASIA C } \\
\hline ASIA D & 2 & 1 & 0.794 \\
\hline ASIA E & 28 & 29 & 0.808 \\
\hline \multirow[t]{2}{*}{ Kyphosis angle $\left(^{\circ}\right)$ before treatment the final follow-up } & $18.77 \pm 2.49$ & $17.97 \pm 2.80$ & 0.301 \\
\hline & $9.31 \pm 1.54^{*}$ & $6.25 \pm 1.04^{*}$ & 0.009 \\
\hline \multicolumn{4}{|l|}{ Loss of angular correction $\left(^{\circ}\right.$ ) } \\
\hline 1 week post-op & $1.10 \pm 1.10$ & $1.25 \pm 1.05$ & 0.701 \\
\hline 3 months post-op & $6.50 \pm 3.50$ & $6.90 \pm 4.30$ & 0.030 \\
\hline 6 months post-op & $7.70 \pm 3.30$ & $9.50 \pm 4.05$ & 0.024 \\
\hline 12 months post-op & $8.95 \pm 4.60$ & $11.55 \pm 4.85$ & 0.012 \\
\hline Final follow-up & $9.60 \pm 1.12$ & $11.85 \pm 1.80$ & 0.006 \\
\hline \multicolumn{4}{|l|}{ Height loss of fused segment (mm) } \\
\hline 1 month post-op & $0.68 \pm 0.23$ & $0.58 \pm 0.33$ & 0.853 \\
\hline 3 months post-op & $1.07 \pm 0.66$ & $1.94 \pm 0.51$ & 0.021 \\
\hline 6 months post-op & $1.90 \pm 0.74$ & $2.48 \pm 1.36$ & 0.015 \\
\hline 12 months post-op & $2.08 \pm 0.85$ & $2.64 \pm 1.42$ & 0.010 \\
\hline Final follow-up & $2.58 \pm 0.45$ & $2.78 \pm 0.95$ & 0.007 \\
\hline Implant subsidence & $3.3 \%(1 / 30)$ & $13.3 \%(4 / 30)$ & 0.122 \\
\hline
\end{tabular}

${ }^{*} P<0.05$ : at the final follow-up vs. before treatment

VAS visual analogue scale, ODI Oswestry Disability Index, ESR erythrocyte sedimentation rate, CRP C-reactive protein, ASIA American Spinal Injury Association 


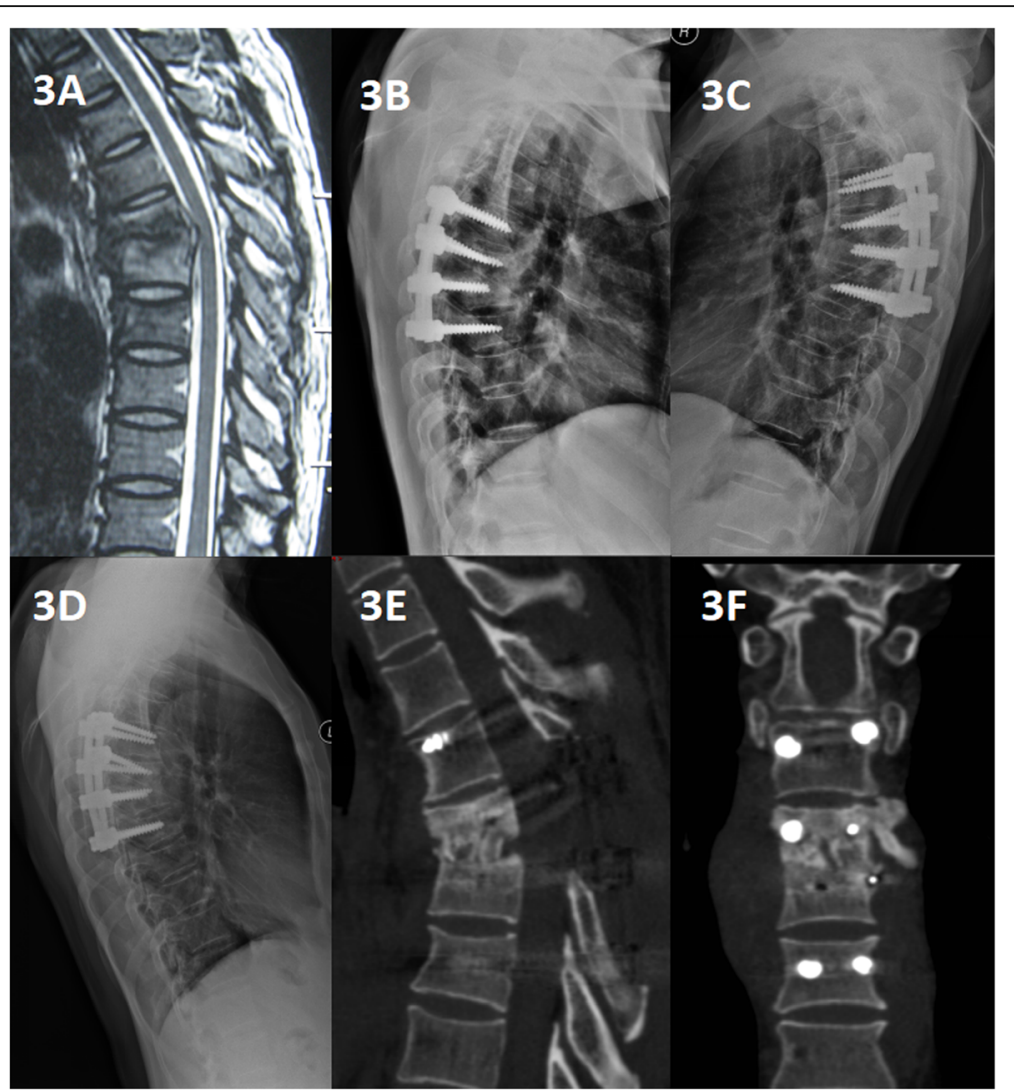

Fig. 3 An 18-year-old man with thoracic spinal tuberculosis (T6-7) underwentsingle-segment posterior debridement and decompression combined with internal fixation. (a) Pretreatment MRI showing destruction of the T6-7 vertebrae and concomitant compression of the spinal cord. (b,c) Immediate postoperative and 6-months radiographs demonstrating posterior debridement, bone graft and internal fixation. (d,e,f) At the 36-month follow-up, plain Xray and CT showed maintenance of the correction and solid fusion

exception of cerebrospinal fluid leakage (one case in group B), fistula (one case in group A), water electrolyte imbalance (three cases in group A, five cases in group B), superficial infection (one case in group B) and mild intestinal obstruction (one case in group A, one case in group B). Implant subsidence occurred in five cases (one case in group A, four cases in group B) and the difference between groups was not significant.

\section{Discussion}

The TB incidence is rising worldwide with 9 million new cases and 2 million deaths per year caused by the increased incidence of AIDS and resistance to antituberculosis drugs [1-6]. Spinal TB remains a common spinal infection. Due to vertebral body collapse or severe deformity, surgical options may be considered appealing in conjunction with the more common conservative treatment options, such as anti-tuberculosis drugs, which are vital. Formal, appropriate and longterm anti-tuberculosis chemotherapy, strict bed rest, and supportive treatment are essential therapies [7-12]. Despite the availability of effective conservative treatments, the goals of current surgical management for spinal TB include debridement of the infected vertebrae, decompression of the spinal cord, correction of deformities, stabilization of the spine and further protection of the spinal cord. Radical debridement and corrective and stabilizing spinal surgery is most effective in cases of active, progressive kyphosis and nonrigid kyphosis [13-15]. The anterior surgery has several disadvantages such as significant blood loss, a longer operation time, and more severe complications and it's more challenging comparing with posterior surgery [16, 17]. Hence, the therapeutic strategy for this disease has been modified in recent years to become more accurate and individualized.

After debridement and decompression, many types of interbody bone grafts may be used to reconstruct the anterior and middle column. Autogenous bone graft, such as an iliac crest or fibula graft, can achieve good bony fusion, however, they can lead to 


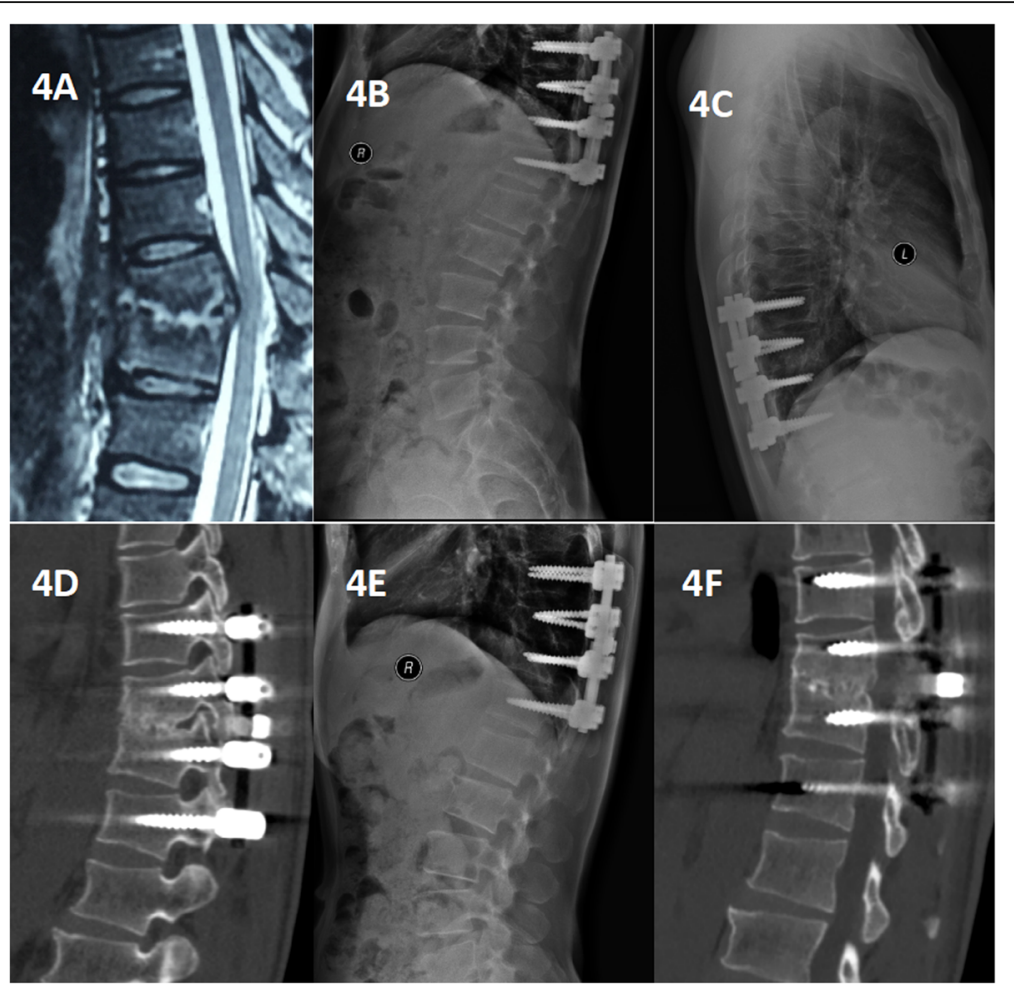

Fig. 4 A 40-year-old man with thoracic spinal tuberculosis (T10-11) underwent posterior debridement and decompression combined with internal fixation. (a) Pretreatment MRI showing destruction of the T10-11 vertebrae and concomitant compression of the spinal cord. (b,c,d) Immediate postoperative and 6-month radiographs and 6-month CT demonstrating posterior debridement, bone graft and internal fixation. (e, f) At the 22-month follow-up, plain X-ray and CT showed maintenance of the correction and solid fusion

complications at the donor site, such as pain, blood loss, hematoma and unhealed wounds. Allografts have been used to avoid donor site complications, but they are associate with decreased arthrodesis rates and increased graft collapse rates. Recently, a number of studies have reported that TMCs showed significant potential for reliable spinal reconstruction, offering excellent bone fusion, adequate sagittal profile maintenance and a low rate of implant-related complications. In our study, TMCs were filled with cancellous bone from excised vertebral lamina and articular processes, which allowed their design to be individualized according to different bone defects [18, 19]. Furthermore, donor site complications did not occur. In addition, their implantation in the defect provided an adequate bony interface to assure spinal stability. The current clinical outcomes showed that solid bony fusion, a satisfactory clinical effect and improved neurological function were obtained in the single-segment titanium mesh group and the transverse process strut group. Although some cases subsided, spinal alignment and stability were still maintained [20].

Cui et al. reported that the thoracic transverse process was longer, thicker, higher and larger than the transverse processes of vertebrae at other spinal levels and could be used as a bone graft. Maria E. K.et al. and other studies demonstrated the quantitative three-dimensional anatomy of the thoracic vertebrae and the discs. Given these anatomical features, the transverse process satisfies the needs of grafts if the bone damage of the infected vertebral body did not exceed $1 / 2$ the vertebral height [21, 22]. The use of the transverse process as a bone graft strut can avoid donor site complications. The transverse process, as an autogenous bone, can be trimmed to the specifications of the bone defect,which not only reduces the difficulty of implantation but also ensures the strength of bone grafting and creates a large interface between the bone graft and the end plate, assuring good fusion. Compared with TMCs [23-28], TPS has superior biomechanical features and multiple transverse bone grafts can be used if the defect requires them. In our study, we used TPS combined with internal fixation; all patients showed satisfactory fusion, and the postoperative kyphosis angle was significantly corrected, indicating that TPS can effectively support the spine. Compared to TMCs, TPS can achieve good clinical outcomes and it presented a 


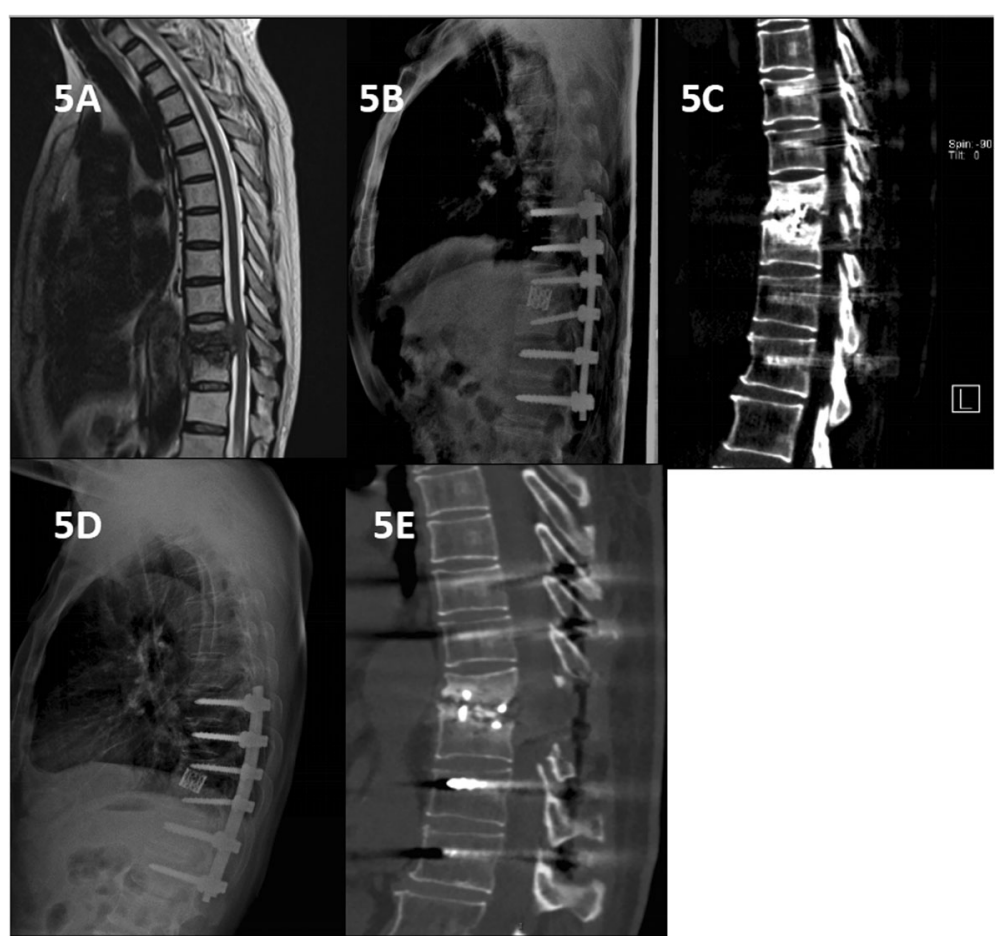

Fig. 5 A 42-year-old man with thoracic spinal tuberculosis (T11-12) underwent posterior debridement and decompression combined with internal fixation. a Pre-treatment MRI showing the destruction of the T11-12 vertebrae and concomitant compression of the spinal cord. $\mathbf{b}$ Immediate postoperative radiographs demonstrating posterior debridement, bone graft and internal fixation. c, d, e At the 24-month follow-up, plain X-ray and CT showed maintenance of the correction and solid fusion, good clinical effect and subsidence of the titanium mesh cage

significantly earlier bony fusion time. As a bone implant, the strength and fusion properties of TPS can effectively reconstruct and maintain spinal stability clinically. Furthermore, the use of TPS can reduce the hospital costs.

\section{Conclusion}

The results of this study showed that when used as a bone graft reconstruct the stability of single-segment thoracic tuberculosis, TPS has a better rate of osseous fusion than TMCs and can provide effective restoration and maintenance of fused segment height and alignment and a lower rate of complications. TPS is an ideal reconstructed bone graft for thoracic single segmental stability. However, we declare that there were a few limitations in the study. First, the study didn't consider the intra and inter observer differences which was associated with bias. Second, the retrospective nature of the small-sample study may be associated with bias. Third, if the bone damage of the infected vertebral body did exceed $1 / 2$ the vertebral height, TPS was not long and strong enough to stabilize which could be prone to subside, or even result in kyphosis and the TMCs or iliac bone graft could be more suitable. Fourth, we need to perform the biomechanical tests between the groups to know the difference of the strength, which could confirm that TPS meets the mechanics needs.
In the future, the prospective, randomized studies with long-term follow-up periods are needed.

\section{Abbreviations \\ TB: Tuberculosis; TPS: Transverse process strut; TMCs: Titanium mesh cages; WHO: World Health Organization; AIDS: Acquired Immune Deficiency Syndrome; ASIA: American Spinal Injury Association; VAS: Visual Analogue Scale; ODI: Oswestry Disability Index; ESR: Erythrocyte sedimentation rate; CRP: C-reactive protein; FU: Follow-up}

\section{Acknowledgements}

Not applicable.

\section{Authors' contributions}

ZWY wrote and modified the manuscript and did the data analysis. LXJ, TK participated in its design and coordination. LXJ, QZX helped in data collecting and coordination. LXJ and TK helped to do the data statistics. QZX conceived the study and helped to draft the manuscript. All authors read and approved the final manuscript.

\section{Funding}

This research did not receive any specific grant from funding agencies in the public, commercial, or not-for-profit sectors.

\section{Availability of data and materials}

The datasets generated and/or analysed during the current study are not publicly available due to the data is confidential patient data but are available from the corresponding author on reasonable request.

\section{Ethics approval and consent to participate}

The study was approved by the the Institutional Review Board of the First Affiliated Hospital of Chongqing Medical University. The written informed consent was obtained from all participants. 


\section{Consent for publication}

Not applicable.

\section{Competing interests}

The authors declare that they have no competing interests.

\section{Author details}

'Department of Orthopedic Surgery, The First Affiliated Hospital of Chongqing Medical University, Chongqing, China. ${ }^{2}$ Department of Pain Management, The First Affiliated Hospital of Chongqing Medical University, Chongqing, China.

Received: 10 July 2019 Accepted: 9 March 2020

Published online: 16 March 2020

\section{References}

1. Moon MS. Managing tuberculosis of spine. Med Progr (Hong Kong). 2004; 31:593-602.

2. China Tuberculosis Control Collaboration. The effect of tuberculosis contro in China. Lancet. 2004:364:417-22.

3. Moon MS. Tuberculosis of spine: contemporary thoughts on current issues and perspective views. Curr Orthop. 2007:21:364-79.

4. McLain RF, Isada C. Spinal tuberculosis deserves a place on the radar screen. Cleve Clin J Med. 2004:71:537-49.

5. Keel M, Ahmad S, Hoppe S. Most influential literature in spinal tuberculosis: a global disease without global evidence. Global. Spine J. 2018:8(1):84-94.

6. Global tuberculosis control: key findings from the December $2009 \mathrm{WHO}$ report. Wkly Epidemiol Rec, 2010;85,69-80.

7. Ekinci S, Agilli M, Ekinci GH, Ersen O. Treatment of thoracic or lumbar spinal tuberculosis complicated by resultant listhesis at the involved segment. Clin Neurol Neurosurg. 2015;128:131-2.

8. Rasjido LV, Vargas MJ, Fajre LE, Luciardi HL. Pott disease in thoracic spine. Medicina (B Aires),2014,74,391(2014)

9. Verdú-López F, Vanaclocha-Vanaclocha V, Gozalbes-Esterelles L, SánchezPardo M. Minimally invasive spine surgery in spinal infections. J Neurosurg Sci. 2014;58:45-56

10. Shi J, Tang $X, X u Y$, et al. Single-stage internal fixation for thoracolumbar spinal tuberculosis using 4 different surgical approaches. J Spinal Disord Tech. 2014;27:E247-57.

11. Wang $X$, Pang $X$, Wu P, Luo C, Shen X. One-stage anterior debridement, bone grafting and posterior instrumentation vs. single posterior debridement, bone grafting, and instrumentation for the treatment of thoracic and lumbar spinal tuberculosis. Eur Spine J. 2014; 23:830-7.

12. Javed G, Laghari AA, Ahmed SI, et al. Development of Criteria Highly Suggestive of Spinal Tuberculosis. World Neurosurg. 2018:S18788750(18)31103-3.

13. Shi S, Ying $X$, Zheng $Q$, et al. Application of cortical bone trajectory screws in elderly patients with lumbar spinal tuberculosis. World Neurosurg. 2018; S1878-8750(18):31122-7.

14. Thakur K, Das M, Dooley KE, Gupta A. The global neurological burden of tuberculosis. Semin Neurol. 2018;38(2):226-37.

15. Brantigan JW, Steffee AD. A carbon fiber implant to aid interbody lumbar fusion. Two-year clinical results in the first 26 patients. Spine (Phila Pa 1976). 1993:18(14):2106-7.

16. Huang $Y$, Lin J, Chen $X$, et al. Correction to a posterior versus anterior debridement in combination with bone graft and internal fixation for lumbar and thoracic tuberculosis. J Orthop Surg Res. 2015;13(1):103.

17. Dunn RN, Ben HM. Spinal tuberculosis. Bone Joint J. 2018;100-B(4):425-31.

18. Zhang $\mathrm{H}$, Zeng $\mathrm{K}$, Yin $\mathrm{X}$, et al. Debridement, internal fixation, and reconstruction using titanium mesh for the surgical treatment of thoracic and lumbar spinal tuberculosis via a posterior-only approach: a 4-year follow-up of 28 patients. J Orthop Surg Res. 2015;10:150.

19. Gao Y, Ou Y, Deng $Q$, et al. Comparison between titanium mesh and autogenous iliac bone graft to restore vertebral height through posterior approach for the treatment of thoracic and lumbar spinal tuberculosis. PLoS One. 2017;12(4):e0175567.

20. Shen $X$, Liu $H$, Wang $G$, et al. The role of single-stage posterior debridement, interbody fusion with titanium mesh cages and shortsegment instrumentation in thoracic and lumbar spinal tuberculosis. $J$ Neurosurg Sci. 2017;61(5):473-80
21. Panjabi MM, Takata K, Goel V, et al. Thoracic human vertebrae . Quantitative three-dimensional anatomy. Spine (Phila Pa 1976). 1991;16(8):888-901.

22. Cui $X$, Zhang Z, Ding Z. Morphometric study of transverse process of thoracic and lum barvertebra and its significance. Chin J Clin Anat. 2015: 23(5):474-6.

23. Kunkel ME1, Herkommer A, Reinehr M, Böckers TM, Wilke HJ. Morphometric analysis of the relationships between intervertebral disc and vertebral body heights: an anatomical and radiographic study of the human thoracic spine. J Anat:2011:219(3),375-387.

24. Tan SH, Teo EC, Chua HC. Quantitative three-dimensional anatomy of cervical,thoracic and lumbar vertebrae of Chinese Singaporeans. Eur Spine. 2004;13:137-46

25. Fletcher JG, Stringer MD, Briggs $C A$, et al. CT morphometry of adult thoracic intervertebral discs. Eur Spine J. 2015;24(10):2321-9.

26. Tanapipatsiri S, Chan DPK. Safety of thoracic transverse process fixation: an anatomic study. Spinal Disord. 1996;9(4):294-8.

27. Jain AK, Jaggi KR, Bhayana H, Saha R. Drug-resistant spinal tuberculosis. Indian J Orthop. 2018;52(2):100-7.

28. Özdoğan S, Yaltırık CK, Düzkalır AH, et al. Spinal tuberculosis mimicking failed Back surgery. Am J Case Rep. 2018;19:249-53.

\section{Publisher's Note}

Springer Nature remains neutral with regard to jurisdictional claims in published maps and institutional affiliations.
Ready to submit your research? Choose BMC and benefit from:

- fast, convenient online submission

- thorough peer review by experienced researchers in your field

- rapid publication on acceptance

- support for research data, including large and complex data types

- gold Open Access which fosters wider collaboration and increased citations

- maximum visibility for your research: over $100 \mathrm{M}$ website views per year

At BMC, research is always in progress.

Learn more biomedcentral.com/submissions 